\title{
Prevalência de Úlcera por Pressão em Pacientes em Risco e o Cuidado no Domicílio após Alta Hospitalar*
}

\author{
Prevalence of Pressure Ulcer in Patients at Risk and Home Care after Hospital Discharge \\ Prevalencia de Úlcera por Presión en Pacientes en Riesgo y Cuidado en Domicilio luego \\ del Alta Hospitalaria
}

\author{
Jaísa Valéria Moro', Maria Helena Larcher Caliri²
}

\begin{abstract}
*Dissertação apresentada ao Programa de Pós-graduação em Enfermagem Fundamental da Escola de Enfermagem de Ribeirão Preto, Universidade de São Paulo para obtenção do título de Mestre em Ciências, em setembro de 2015.
\end{abstract}

Pacientes hospitalizados que têm risco para úlcera por pressão (UP) ou apresentam o problema, após a saída do hospital, necessitam de cuidados domiciliares para o manejo da situação. A atenção domiciliar, no âmbito do Sistema Único de Saúde, é uma modalidade de atenção à saúde, em que um conjunto de ações para promoção à saúde, prevenção e tratamento de doenças e reabilitação pode permitir a continuidade dos cuidados. O presente estudo é transversal, com abordagem quantitativa, e foi aprovado pelo Comitê de Ética em Pesquisa da Escola de Enfermagem de Ribeirão Preto. Os objetivos foram: descrever o perfil sociodemográfico e de saúde de pacientes que tinham risco para UP e que receberam alta de um hospital de urgência; identificar o nível de risco para UP após a saída da instituição e encontrar a prevalência de UP, as características da lesão e o contexto do cuidado domiciliar. A coleta de dados foi realizada no domicílio no segundo mês após a alta. Participaram da pesquisa 23 pacientes, com idade média de 50,07 anos, cor branca, maior frequência do sexo feminino, procedentes de Ribeirão Preto. A maioria das participantes era pensionista, casada, com renda familiar mensal de um a dois salários-mínimos e morava com esposo e filhos. O problema de saúde mais frequente foi trauma de crânio, seguido por acidente vascular cerebral. Dentre os que necessitavam de algum cuidado no domicílio, os cuidadores principais eram esposos (45\%). A média dos escores da Escala de Braden para 13 pacientes em risco para UP foi 15,46, enquanto para 10 sem risco, 22. Dentre as participantes em risco, houve predomínio dos idosos (61,5\%). A prevalência de UP foi 21,7\% e, das 8 UP, 50\% localizavam-se na região sacral. Em relação ao contexto do cuidado no domicílio, dos 21 pacientes que receberam encaminhamentos após a alta, 18 (78,3\%) eram acompanhados nos serviços deaúde. Dezesseis sujeitos $(69,5 \%)$ referiram ter recebido orientações sobre a prevenção da UP durante a internação. No domicílio, nove pacientes recebiam atenção domiciliar com visita domiciliar, e desses, seis tinham risco para UP e quatro já apresentavam a lesão. Uma pessoa com UP e residente em outro município não recebia atenção domiciliar. Em 44,4\% dos casos, as visitas domiciliares foram realizadas por enfermeiros, auxiliares de enfermagem e médicos. Quanto às medidas de prevenção, em todos os pacientes em risco, era realizada a mudança de decúbito, oito $(61,5 \%)$ sentiam alívio da pressão quando sentados, quatro $(30,8 \%)$ usavam uma almofada para sentarem-se, sete $(53,8 \%)$ faziam alívio da pressão dos calcâneos e três $(23,1 \%)$ usavam lençol móvel para movimentação no leito. Dos oito pacientes em risco que não tiveram UP durante a internação, nenhum desenvolveu úlcera após a alta. Concluiu-se que os escores da Escala de Braden permitem a detecção da vulnerabilidade dos pacientes para UP e apontam a necessidade de atenção domiciliar para favorecer a continuidade do cuidado após a alta. Por outro lado, deve-se melhorar as orientações para o cuidado preventivo no ambiente hospitalar, além da criação dos mecanismos de comunicação entre os serviços para facilitar a continuidade do cuidado e a segurança do paciente.

DESCRITORES: Estomaterapia. Úlcera por pressão. Prevalência. Assistência domiciliar.

\footnotetext{
${ }^{1}$ Enfermeira na Prefeitura Municipal de Itatiba; Mestre em Ciências pela Escola de Enfermagem de Ribeirão Preto da Universidade de São Paulo USP_ Ribeirão Preto (SP), Brasil. Endereço para correspondência: Rua Alexandre França, 116 - Parque João de Vasconcellos - CEP: $13172-580$ - Sumaré (SP), Brasil-E-mail: ja_valeria@hotmail.com

²Docente da Escola de Enfermagem de Ribeirão Preto da USP - Ribeirão Preto (SP), Brasil.

Artigo recebido em: 04/10/2015 - Aceito para publicação em: 14/10/2015
} 